\title{
Impact of species identity and phylogenetic relatedness on biologically-mediated plant- soil feedbacks in a low and a high intensity agroecosystem
}

\section{Authors: Zachariah J. Miller \& Fabian D. Menalled}

This is a postprint of an article that originally appeared in Plant and Soil on December 2014. The final publication is available at Springer via http://dx.doi.org/10.1007/s11104-014-2336-x.

Miller, Zachariah J., and Fabian D. Menalled. Impact of species identity and phylogenetic relatedness on biologically-mediated plant-soil feedbacks in a low and a high intensity agroecosystem. Plant and Soil. December 2014.

https://dx.doi.org/10.1007/s11104-014-2336-x 


\title{
Impact of species identity and phylogenetic relatedness on biologically-mediated plant-soil feedbacks in a low and a high intensity agroecosystem
}

Zachariah J. Miller: Western Ag Research Center, Montana State University, Corvallis, Montana

Fabian D. Menalled: Department of Land Resources and Environmental Sciences, Montana State University, Bozeman, Montana

\begin{abstract}
Aims Plant species-specific effects on soil biota and their impacts on subsequent plant growth, i.e. plantsoil feedbacks (PSFs, henceforth), are major drivers in natural systems but little is known about their role in agroecosystems. We investigated the presence and mag-nitude of PSFs in two contrasting agricultural settings and tested the importance of species identity and phylo-genetic relationships in determining PSFs.

Methods We compared PSFs that developed from an intensified agricultural site and a nearby non-cultivated pasture. Four weed and seven crop species were grown in soil inoculated with either biologically active or sterilized soils from each system. Four crop response spe-cies were grown to estimate PSFs.

Results PSFs were species-specific. The identity of currently- and previously-planted species and their interactions explained over $80 \%$ of the variation in feed-backs. Biota from the intensified agricultural site produced negative feedbacks in three of the four response species. Phylogenetic relationships partially explained PSFs.

Conclusions PSFs can alter crop growth and may be altered by agricultural practices. The species-specific effect to soil biota should be taken into account when assessing the extent to which crop and weed species could influence subsequent plant growth.
\end{abstract}

\section{Introduction}

Understanding the patterns and mechanisms by which plants alter belowground processes and how these changes, in turn, modify plant growth is a central tenet of basic and applied ecology (Klironomos 2002). Plant growth can modify the soil in a species-specific manner through changes in abiotic parameters such as nutrient availability (Clark et al. 2005), soil physical and chem-ical properties (Ehrenfeld et al. 2005), and soil moisture (Nielsen et al. 2005). Plants can also have species-specific effects on soil biota by modifying the composition and abundance of pathogenic and mutualistic organisms (Wolfe and Klironomos 2005). These below ground changes can, in turn, impact the growth and competitive ability of plants that subsequently occupy that site, completing the plant-soil feedback (PSF, henceforth) loop.

Legacy effects of PSFs can either enhance or de-crease the growth and fitness of subsequent plants which respond to these altered soil parameters in species- 
specific ways. The direction and specificity of PSFs can drive plant population and community dynamics. For example, PSFs that enhance subsequent growth of the same plant species relative to other species have been associated with an increase in between-species fitness differences and an overall decrease in local community diversity (Callaway et al. 2004). On the other hand, the accumulation of pathogenic microbes, parasites, and herbivores has been associated with PSFs that reduce conspecific growth relative to the effects on growth of other species, enhancing species turnover rates and increasing community diversity (Reynolds et al. 2003; Bever 2003). These PSFs seldom occur in isolation and their net effects play a vital role in ecosystem organization, functioning, and dynamics (van der Putten et al. 2013).

While much research has been conducted on the role of biologically mediated PSFs as ecological drivers in wild plant communities, little is known about their function and magnitude in agroecosystems. This knowledge gap is surprising given that the concept of minimizing the negative impacts of PSFs is central to the practice of crop rotation which, by growing sequences of crops that differ in taxonomy and disease susceptibility, minimizes the impact of narrow host range pathogens (Curl 1963).

Two complementary lines of evidence suggest that biologically mediated PSFs may play important roles in annual cropping systems. First, negative PSF (i.e. growth reduced by soil biota) are commonly observed in non-crop annual species (Kulmatiski et al. 2008). These negative PFSs are consistent with the predictions of the resource-allocation hypothesis that holds that shorted-live species invest resources in growth rather than defense (Herms and Mattson 1992). Second, practices associated with agricultural intensification such as tillage, fertilizers, and monocultures affect the abundance and diversity of soil biota and may alter PSF (de Vries et al. 2013; Postma-Blaauw et al. 2010; Van Groenigen et al. 2010).

Understanding the importance of biologicallymediated PSFs in determining the growth of crops species may provide important insights into the design of ecologically-based agricultural management systems that reduce dependence on off-farm inputs. For example, while most weed management aims at minimizing weed abundance near the time a crop is planted and for a short period thereafter (Zimdahl 2004), biologicallymediated legacies may linger after crops and weeds have been removed (Curl 1963; Kulmatiski and Beard
2011), with negative plant-soil interactions accumulating over time (Diez et al. 2010; Hawkes et al. 2013). A better understanding of the ecological implications of PSFs in agroecosystems could help minimize their negative impact on crop growth or even promote positive interactions by limiting plant disease and enhancing plant health.

To fill this knowledge gap, this study 1) compared biologically-mediated PSFs generated by living inocula collected in a highly disturbed agricultural site and a nearby non-cultivated pasture, and 2) assessed the relative importance of phylogenetic relatedness in determining the strength of PSFs. We hypothesized that, first, biologically-mediated PSFs reduce annual crop growth as negative feedbacks dominate early successional systems (Kulmatiski et al. 2008), particularly in monocultures (Bakker et al. 2013). Second, PSFs that develop in the cultivated agricultural field more strongly inhibit crop growth than those from the less disturbed site. This hypothesis is based on the fact that soil disturbance practices such as cultivation decrease mycorrhizal abundance (Drijber et al. 2000). Finally, we hypothesized that PSFs are species-specific with closely related species generating more inhibitory feedbacks than distantly related species. We based this last hypothesis on previous observations that phylogenetic relatedness plays a dominant role in determining PSFs in grasslands (Brandt et al. 2009) and that phylogeny has been used to explain associations between plants and beneficial (Reinhart et al. 2012) as well as antagonistic (Gilbert and Webb 2007) microbial species.

\section{Material and methods}

Origin of soil inocula and seeds The experiment was conducted with soils collected at a crop field and an adjacent grazed non-cultivated pasture located at the Fort Ellis Research Center, Montana State University, Bozeman, MT $\left(45^{\circ} 40^{\prime} \mathrm{N}, 111^{\circ} 2^{\prime} \mathrm{W}\right.$; altitude $\left.1468 \mathrm{~m}\right)$. The two sites are within a $300 \mathrm{~m}$ radius and environmental conditions are similar between the two sites. Long-term mean monthly air temperature ranges between -5.7 and $18.9{ }^{\circ} \mathrm{C}$. Mean annual precipitation is $465 \mathrm{~mm}, 60 \%$ of which occurs between April and September. The soil at the site is a Blackmore silt loam with 0 to $4 \%$ slopes and contains $250 \mathrm{~g} \mathrm{~kg}^{-1}$ sand, $500 \mathrm{~g} \mathrm{~kg}^{-1}$ silt, and $250 \mathrm{~g} \mathrm{~kg}^{-1}$ clay at 0 to $15 \mathrm{~cm}$. The 
two sites differed in disturbance regimes, plant diversity, and agro-chemical inputs.

For 6 years prior to this study, the crop field had been continuously planted to spring wheat (Triticum aestivum L.) seeded at $90 \mathrm{~kg} \mathrm{ha}^{-1}$ with the field tilled each fall following harvest (see Sainju et al. 2010 for a description of nutrient, herbicide, and other management practices). Plant species diversity at this field was low due to continuous wheat production and the intensive use of tillage and herbicides. Triticum aestivum dominated the plant community, comprising 96 to $100 \%$ of the plant biomass.

The pasture was located approximately $300 \mathrm{~m}$ south of the crop field, had never been tilled, and was periodically grazed by sheep and cattle. The plant community was composed of a diverse mixture of perennial species (93.6\% of species). In total, 46 species were present, with an average of 10.9 species $\mathrm{m}^{-2}$. Monocots (grasses and sedges) were more abundant (average cover $=50 \%$ ) but less species-diverse (nine species) than dicots (average cover $=39 \%, 37$ species). Dominant (mean cover $>10 \%$ ) grasses included Agropyron cristatum L. (crested wheatgrass), Bromus inermis Leyss (smooth brome), Festuca idahoensis Elmer (Idaho fescue), and Poa compressa L. (Canada bluegrass). Common forbs included Erigeron spp. (fleabane), Geranium viscosissimum Fisch. and C.A. Mey. ex C.A. Mey (sticky purple geranium), Phlox spp., Solidago spp., and Lupinus spp. Due to the unique land-use history of the selected fields and the labor-intensive nature of this study (see below), we could not replicate contiguous continuous T. aestivum and undisturbed pasture systems. Therefore, our conclusions regarding the impacts of agricultural intensification on PSFs are limited to the study sites.

Living field inocula were obtained from the agricultural crop field (AG, henceforth) and non-cultivated pasture site (NC, henceforth) on May 15th 2010 by collecting soil samples with a soil corer $(0-12 \mathrm{~cm}$ depth, $8 \mathrm{~cm}$ diameter). To encompass a range of soil biological conditions, 50 samples were taken at each site over a 1 ha area along transects separated by approximately $4 \mathrm{~m}$. Samples from each system were pooled, sifted through $1 \mathrm{~cm}^{2}$ mesh, and air-dried for 2 weeks. To isolate effects of soil biological communities, a subset of each soil mixture was subjected to one of two treatments: 1) a biologically inactive (BA-, henceforth), i.e. sterilization treatment conducted both prior the conditioning phase and between the conditioning and response phases and consisting of two $1 \mathrm{~h}$ steam pasteurizations at $120{ }^{\circ} \mathrm{C}$ separated by a $48 \mathrm{~h}$ period in which the soil was covered and sealed to prevent contamination or 2) a biologically active soil (BA+, henceforth). The resulting four soil mixtures, BA-/+ in both $\mathrm{AG}$ and $\mathrm{NC}$, were used as inoculation treatments.

Crop and weed species used in this study were selected for their economic importance and to represent a range of taxonomic and phylogenetic diversity (Table 1, Fig. 1). Weed species included locally collected seeds of four species: Thlaspi arvense L. (field pennycress), Lactuca serriola L. (prickly lettuce), Bromus tectorum L. (cheatgrass), and Setaria viridis L. (green foxtail). Crop species included Lens culinaris Medik. (lentils), Carthamus tinctorius L. (safflower), T. aestivum, Hordeum vulgare L. (barley), Pisum sativum L. (pea), Beta vulgaris L. (beet), and Brassica hirta L. (mustard).

Experimental setup This study was conducted in two separated greenhouses at Montana State University, Bozeman, MT. Greenhouse lights supplemented ambient light to provide a $16-\mathrm{h} / 8-\mathrm{h}$ light/dark photoperiod, with treatments equally replicated across greenhouses, and pots randomly located to treatments within greenhouses. Temperature in the greenhouses was kept between $10^{\circ} \mathrm{C}$ (night) and $25{ }^{\circ} \mathrm{C}$ (day). Pots (volume $=2.5 \mathrm{~L}$ ) were filled with a steam-sterilized at $120{ }^{\circ} \mathrm{C}$ soil mixture $(2: 1: 1$ sand, topsoil, and peat by volume). Following Smith et al. (2011), sterilization consisted of $4 \mathrm{~h}$ at $170{ }^{\circ} \mathrm{C}$. To control for the potential abiotic differences in soil inocula, we added to each pot a small amount $(100 \mathrm{ml}=4.0 \%$ by volume $)$ of either biologically active or sterilized inoculum from either site. Adding relatively small amounts of inocula to a homogeneous sterile soil mixture avoids problems of higher nutrient availability associated with steam sterilization. While the use of small amounts of inocula could result in diluted effects, Hol et al. (2013) observed that this approach can generate measurable PSFs.

The experiment consisted of two phases, a conditioning phase and a response phase (Fig. 2). The goal of the conditioning phase was to allow each of the four weed species and seven crop species to alter soil biological communities after being inoculated with one of the four inocula treatments. A plant-free control was included during the conditioning phase to assess the importance of plant growth in determining the development of biologically-mediated feedbacks. The response phase evaluated the impact of the presence and source of an 
Table 1 Plant species, common name, functional (Funct.) group, and seedling densities used in the conditioning and response phases of the experiment

\begin{tabular}{|c|c|c|c|c|c|}
\hline Species & Common Name & Funct. Group & $\begin{array}{l}\text { Conditioning Phase } \\
\text { Density } 1 \text { st planting }\end{array}$ & $\begin{array}{l}\text { Conditioning Phase } \\
\text { Density 2nd planting }\end{array}$ & $\begin{array}{l}\text { Response Phase } \\
\text { Density }\end{array}$ \\
\hline Beta vulgarus & Beets & Crop & 35 & 43 & \\
\hline Lactuca serriola & Prickly lettuce & Weed & 18 & 32 & \\
\hline Carthamus tinctorius & Safflower & Crop & 25 & 17 & 20 \\
\hline Thlaspi arvense & Field pennycress & Weed & 10 & 27 & \\
\hline Brassica hirta & White mustard & Crop & 48 & 12 & 30 \\
\hline Lens culinaris & Lentils & Crop & 29 & 33 & 15 \\
\hline Pisum sativum & Pea & Crop & 11 & 8 & \\
\hline Setaria viridis & Green foxtail & Weed & 15 & 36 & \\
\hline Bromus tectorum & Cheatgrass & Weed & 28 & 56 & \\
\hline Hordeum vulgare & Barley & Crop & 20 & 13 & \\
\hline \multirow[t]{2}{*}{ Triticum aestivum } & Wheat & Crop & 30 & 12 & 15 \\
\hline & Plant-free control & & 0 & 0 & \\
\hline
\end{tabular}

inoculum, and of the conditioning phase species identity on the growth of four crop species: T. aestivum, C. tinctorius, L. culinaris, and B. hirta. Each treatment was replicated four times, for a total of 768 pots $(11$ species or fallow during the conditioning phase $\times 4$ species during the response phase $\times 2$ soil types $\times 2$ inoculum treatments $\times 4$ replicates) with pots randomly assigned to treatments. During the whole experiment pots were carefully watered to minimize pot to pot contamination due to splashing.

The conditioning phase consisted of two 1month growing periods separated by a 2 weeks fallow. Plant densities were chosen to minimize differences in biomass production among species in the conditioning treatments (Table 1). All pots were seeded with 15 to 50 seeds, depending on species treatment, and thinned 10 days after planting to the targeted species density. Soils remained in the pots between the first and second conditioning period and a minimum soil disturbance occurred during the course of this study to minimize changes in soil biotic conditions, which could have modified the pool of organic and mineralizable nutrients. At the end of each 1-month conditioning
Fig. 1 Phylogeny of

conditioning and response phase species used to evaluate the impact of species identity and system stability on biologically mediated plant-soil feedbacks

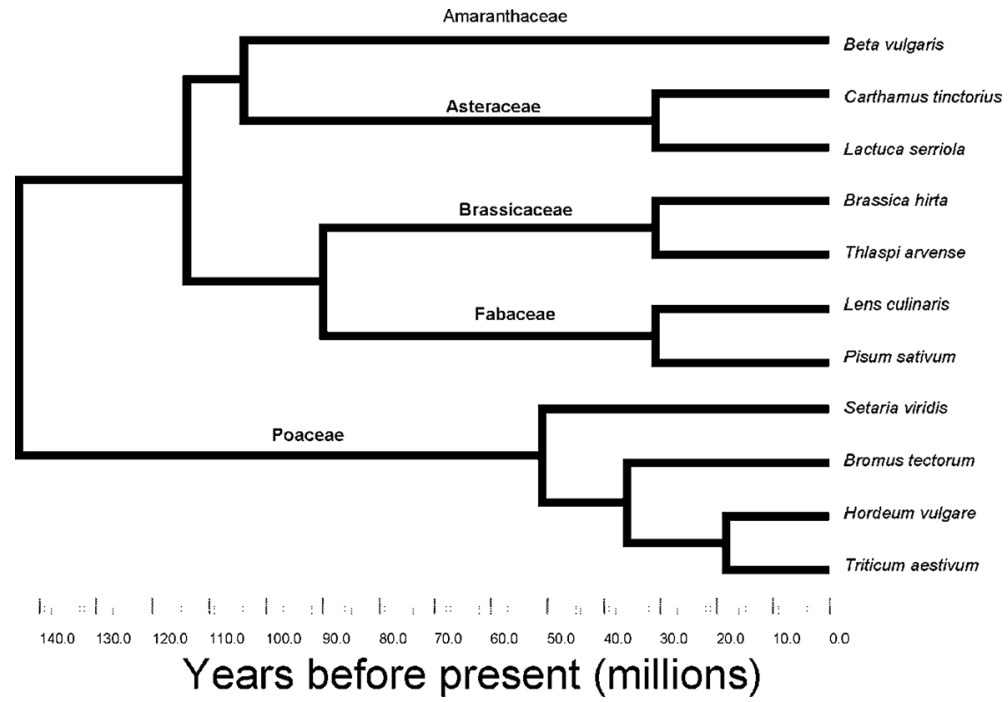




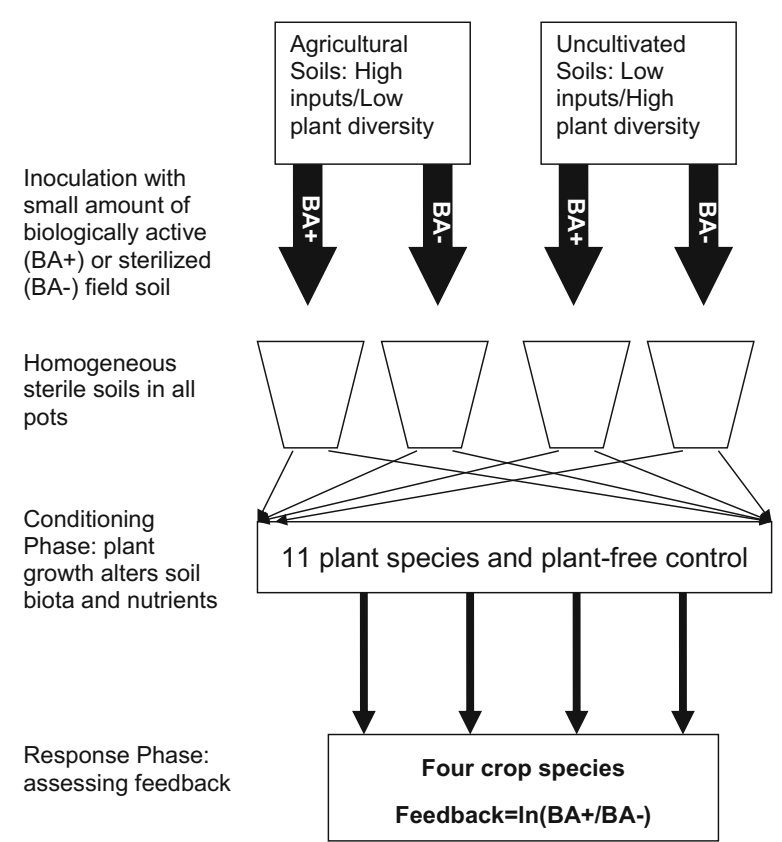

Fig. 2 Experimental design used to test the role of species identity and system stability in mediating plant-soil feedbacks impacts on plant growth

period, all above ground biomass was harvested, dried to constant weight, and weighted to the nearest $0.01 \mathrm{~g}$.

Following a 2-week fallow, the four response phase species were planted into each of conditioning species and inoculation treatments. All pots were thinned 7 days after planting to the targeted densities (Table 1). Plants were grown until onset of flowering, at which time all above ground biomass was harvested, dried to constant weight, and weighted to the nearest $0.01 \mathrm{~g}$.

Data analysis Following Brinkman et al. (2010), pots were randomly paired within each greenhouse, response and conditioning phase species, and inoculum treatment combination, to calculate PSF as:

$\operatorname{PSF}_{i j}=\log \left(\operatorname{biomass}_{i j}(\mathrm{BA}+) / \operatorname{biomass}_{i j}\left(B A^{-}\right)\right)$

where biomass $_{i j}(\mathrm{BA}+)$ represents the biomass of species $i$ growing in soil that received a biologically active inoculum and that has been conditioned by species $j$, and (biomass $\mathrm{ij}_{\mathrm{ij}}(\mathrm{BA}-$ ) represents the biomass of species $i$ growing in soil that received an sterile inoculum and that has been conditioned by species $j$. $\mathrm{PSF}_{i j}$. is centered on zero when the plant biomass in pots receiving biologically active inoculum is equal to the biomass in soil receiving sterilized inoculum. The ratio is positive if the presence of a biologically active inoculum increases plant biomass relative to the sterilized controls and negative if the active inoculum decreases plant biomass. This approach provides an estimate of PSFs that it is independent of plant size and that allows comparisons between species and environments.

To test specific hypotheses, analyses were conducted on subsets of the data. The extent to which feedbacks require prior plant growth to develop was tested by analyzing the feedbacks in the plant free controls conditioning treatment separately. Specifically, we tested that feedback values do no differ from zero. The ANOVA model used included the fixed effects of inoculum source and response phase treatments.

To test our first and second hypotheses, the PSF data was analyzed excluding data from plant free controls. The ANOVA model included the fixed effects of inoculum source as well as conditioning and response phase species identity. This analysis indicated that there were two significant negative outliers, occurring in the T. aestivum response phase that followed either T. aestivum or $H$. vulgare when receiving the biologically active inoculum from the crop field (Fig. 3). A visual observation indicated that these outliers corresponded to pots that exhibited symptoms of seedling disease (damping-off). To accommodate for the ANOVA assumptions, both outliers were removed from all further analyses.

Our third hypothesis was tested by regressing feedback values with the pairwise phylogenetic distances between conditioning and response phase species. The phylogenetic distances were calculated as the sum of the branch lengths between a given specific pair of conditioning and response phase species (Fig. 1). The relationships among species and divergence times in the phylogeny were based on published sources (Vicentini et al. 2008; Stevens 2014). The pair-wise distance measures were transformed as $\ln ($ distance +1$)$ prior to the analysis. The ANCOVA model used in this analysis controlled for differences between the conspecific feedbacks in each response phase by soil inocula treatment combination (random intercepts). This analysis also tested the correlation of feedbacks with phylogenetic distance and if the correlation differed among response phase species, soil inocula treatments, or their interaction. As before, outliers were removed prior to the phylogenetic regression. All analyses were done using R statistical software (R Development Core Team 2008). 


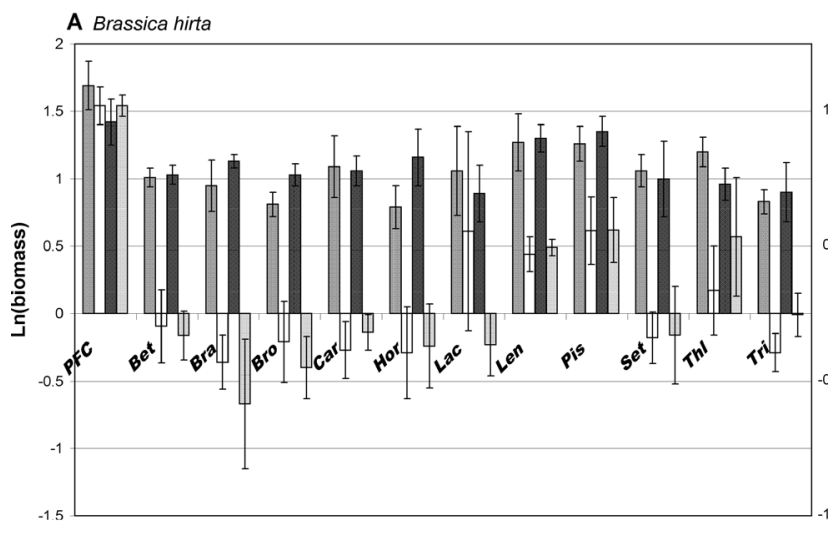

B Carthamus tinctorius
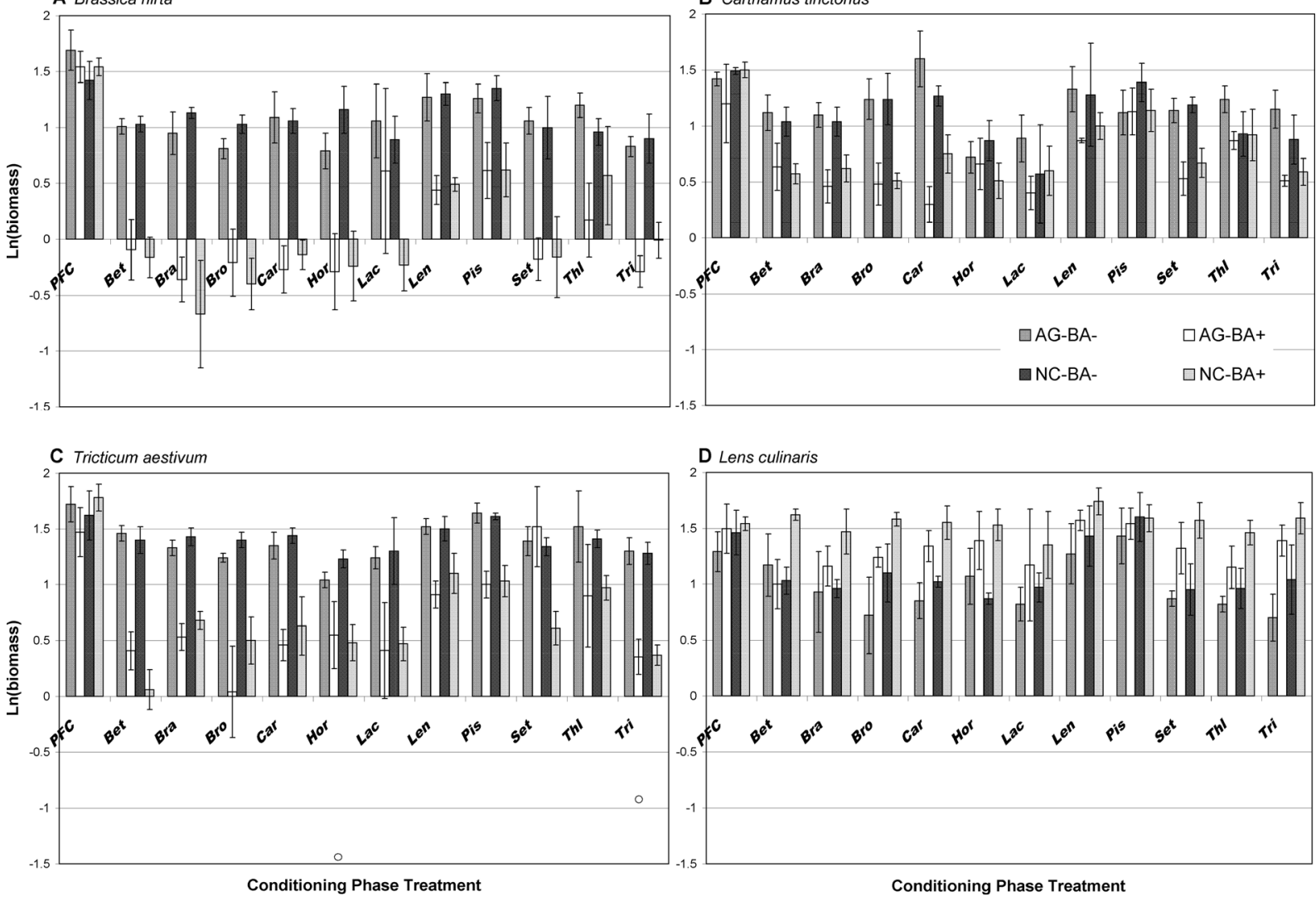

Fig. 3 Mean $\ln$ plant biomass (y-axis) for each response phase species across conditioning species phase and soil inoculation treatments, noted by shading in bars (see key in Fig. 2a). Error bars depict 1 standard error. Significant outliers are shown as open circles. Conditioning phase species are abbreviated as: $P F C$ plantfree control, Bet Beta vulgaris, Bra Brassica hirta, Bro Bromus

tectorum, Car Carthamus tinctorius, Hor Hordeum vulgare, Lac Lactuca serriola, Len Lens culinaris, Pis Pisum sativum, Set Setaria viridis, Thl Thlaspi arvense, Tri Triticum aestivum. AG agricultural field, $N C$ non-cultivated pasture, $B A+$ biologically active inoculum, $B A$ - biologically inactive inoculum

\section{Results}

Impacts of plant growth on plant soil feedbacks The presence of plant growth was required for feedbacks to occur as no PSFs were detected in the absence of plant growth during the conditioning phase, regardless of the presence and source of a biologically active inoculum (inoculum source main effect $\mathrm{F}_{1,48}=0.01, p>0.9$ ) (Plant free control - PFC - in Fig. 3). PSFs were similar among response phase species $\left(\mathrm{F}_{3,24}=2.0, p>0.1\right)$ but differed between inoculation source $\left(\mathrm{F}_{1,24}=6.5, p<0.05\right)$ with mean feedbacks -0.10 (95\% C.I. -0.26 to 0.05 ) with the biota from agricultural soils and 0.10 (95\% C.I. -0.06 to 0.25 ) in uncultivated soil.

Importance of inoculum source in determining plantsoil feedback When plant growth occurred during the

conditioning phase, biologically mediated feedbacks altered biomass in nearly $80 \%$ (69 of 88 ) of all treatment combinations (Fig 3). In partial accordance with our first hypothesis, in the three non-leguminous response phase species the presence of soil organisms reduced plant growth in $86.4 \%$ (57 of 66) of the treatments. The negative feedbacks were most pronounced in $T$. aestivum and B. hirta where addition of soil biota reduced biomass in over $97 \%$ of the treatments. In contrast, the addition of soil biota never reduced the biomass of L. culinaris and increased the growth of this species in $54.5 \%$ (12 of 22) of the conditioning and inoculum source treatments.

In partial agreement with our second hypothesis, the feedbacks that developed with the biologically active inoculum from the crop field were more inhibitory than those occurring when the pasture inoculum was used for 
all response phase species except $B$. hirta. This differential response resulted in a 3-way interaction between inoculum source, conditioning phase species identity, and response phase species identity $\left(\mathrm{F}_{30,263}=1.7\right.$, $p<0.05$ ). Thus, the effects of inoculum source and conditioning phase species treatments on PSFs were analyzed separately for each response phase species.

Results indicated that inoculum effects were consistent across L. culinaris, C. tinctorius, and T. aestivum, and data from these three species were pooled and reanalyzed (Table 2a). This three-species model indicated that inoculum source consistently affected PSFs. This effect was similar across response phase and conditioning phase species treatments as seen in the nonsignificant interaction involving these terms and inoculum source (Table 2a). Specifically, PSFs that developed in pots receiving the pasture inoculum were less inhibiting of plant growth, when negative, and more promoting of growth, when positive, than those observed in pots receiving the agricultural inoculum. Averaged across these three response phase species, the differences in feedbacks resulted in an increase of crop biomass of 10 to $21 \%$ (95\% C.I.) in the pasture inoculated pots relative to the soils inoculated with the agricultural inoculum.

Table 2 Results of an ANOVA test assessing the effects of response and conditioning phase species identity and inoculum source on plant soil feedbacks in a) Carthamus tinctorius, Triticum aestivum, and Lens culinaris and b) Brassica hirta

\begin{tabular}{llccl}
\hline Source & df & MS & F & Significance \\
\hline a) & & & & \\
Response phase spp. (R) & 2 & 30.68 & 418.96 & $* * *$ \\
$\quad$ Inoculum source (I) & 1 & 0.94 & 12.8 & $* * *$ \\
$\quad$ Conditioning phase & 10 & 0.41 & 5.6 & $* * *$ \\
$\quad$ spp. (C) & 2 & 0.01 & 0.2 & \\
RxI & 20 & 0.26 & 3.6 & $* * *$ \\
RXC & 10 & 0.09 & 1.3 & \\
IxC & 20 & 0.09 & 1.3 & \\
$\quad$ RxIxC & 196 & 0.07 & & \\
$\quad$ Error & & & & \\
b) $\quad 1$ & 0.15 & 1.5 & \\
Inoculum source (I) & 1 & 0.62 & 6.1 & $* * *$ \\
Conditioning phase & 10 & & & \\
$\quad$ spp. (C) & 10 & 0.28 & 4.8 & $* *$ \\
CxI & 66 & 0.10 & & \\
Error & & & & \\
\hline
\end{tabular}

Significance of effects noted as $* * *=p<0.001 ; * *=p<0.01$
In $B$. hirta, we failed to detect consistent differences in the impact of inoculum source on PSF (Table 2b). In eight of the 11 conditioning phase species treatments, feedbacks were similar between agricultural and pasture inocula. For two (L. serriola and B. hirta) of the remaining three conditioning treatments, the non-cultivated pasture inoculum generated more inhibitory feedbacks than the agricultural inoculum (Fig. 4). Finally, in soil conditioned by $T$. arvense, another mustard species, the feedback from the non-cultivated pasture inoculum were less damaging than that of the cultivated agricultural inoculum (Fig. 4).

Role of species identity and phylogenetic relatedness in determining plant soil feedbacks In partial accordance with our third hypothesis, species identity played a role in determining PSFs with response phase identity, conditioning species identity, and their interaction all highly significant $(p<0.001)$ and explaining $81 \%$ of the variation in feedbacks. The relative effects of the feedbacks generated by a given conditioning phase species varied considerably among response phase species. In general, the strongest inhibitory feedbacks developed when the phytometer species grew in soil conditioned by the same or a closely related species (Figs. 4 and 5).

Results of the phylogenetic analysis indicated that PSFs were positively correlated with increasing phylogenetic distance between the response and conditioning phase species $\left(\mathrm{F}_{1,332}=24.5, p<0.01\right)$. However, phylogenetic distance was a poor predictor of feedback values, explaining $1.7 \%$ of the total variation. The slope of the relationship (0.05, $95 \%$ C.I. $0.03-0.08)$ between feedback values and log-transformed phylogenetic distance was similar among conditioning phase and inoculum source treatments (all interactions, $P>0.1$ ). The estimates of the slope suggest that much of the change in feedbacks occurs between phylogenetic distances of zero (conspecifics) and 50 to 60 million years (conditioning species within the same family as the response phase species) with little change in feedbacks with greater phylogenetic distance. When conditioning by conspecific species treatments were removed from the analysis, the relationship between phylogenetic distance and feedbacks varied across response phases and inoculum treatment combinations $\left(\mathrm{F}_{3,301}=4.2, p<0.01\right)$. To investigate the variation in the relationship between phylogenetic distance and feedbacks generated by the ten heterospecific species utilized, we analyzed the correlation in each response phase species separately. 


\section{Inoculum Source}

\section{Agricultural}

\section{Non-cultivated pasture}

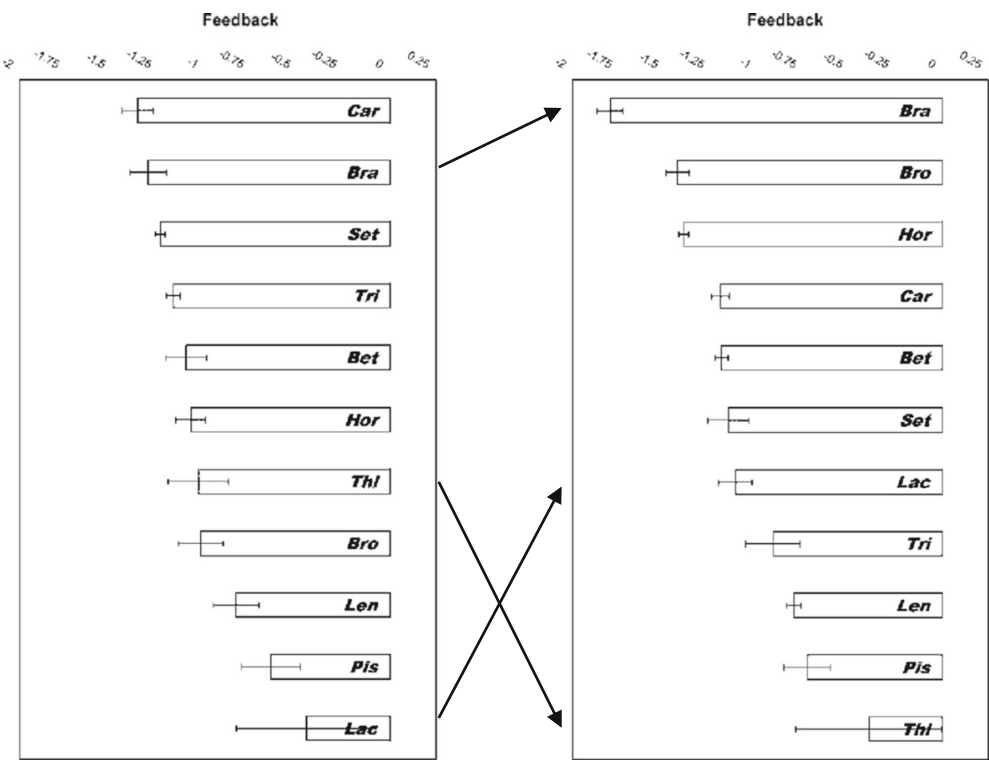

Fig. 4 Mean and standard error feedback values [calculated as the natural $\log$ of the response ratio $=\mathrm{Ln}($ biomass $(\mathrm{BA}+) /$ biomass (BA-))] observed in Brassica hirta response phase treatment for each conditioning phase treatment (labeled on y-axis and ordered from most negative at top to least negative at bottom) and inoculation treatment. Within each inoculum source treatment, conditioning species are ordered from most negative at top to least negative at bottom. Arrows indicate significant differences in feedback values between inoculation sources. $A G$ agricultural field, $N C$ non-cultivated pasture, $B A+$ biologically active inoculum, $B A$ - biologically inactive inoculum. Conditioning phase species are abbreviated as: Bet Beta vulgaris, Bra Brassica hirta, Bro Bromus tectorum, Car Carthamus tinctorius, Hor Hordeum vulgare, Lac Lactuca serriola, Len Lens culinaris, Pis Pisum sativum, Set Setaria viridis, Thl Thlaspi arvense, Tri Triticum aestivumm
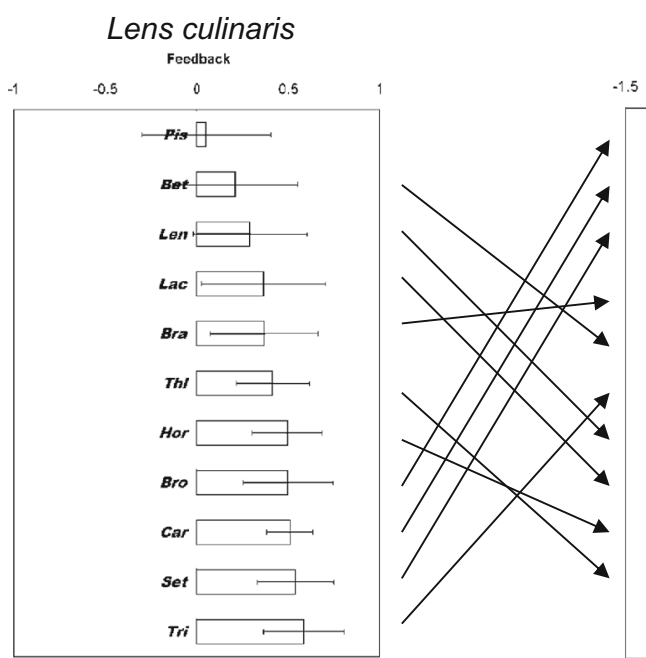

Carthamus tinctorius Feedback

Fig. 5 Mean and standard error feedback values [calculated as the natural $\log$ of the response ratio $=\operatorname{Ln}($ biomass $(\mathrm{BA}+) /$ biomass(BA-))] on Lens culinaris, Carthamus tincorius, and Triticum aestivum. For each phytometer species, conditioning phase treatments are ordered from most negative at top to least negative at bottom. Arrows denote significant differences in aestivumm
Triticum aestivum

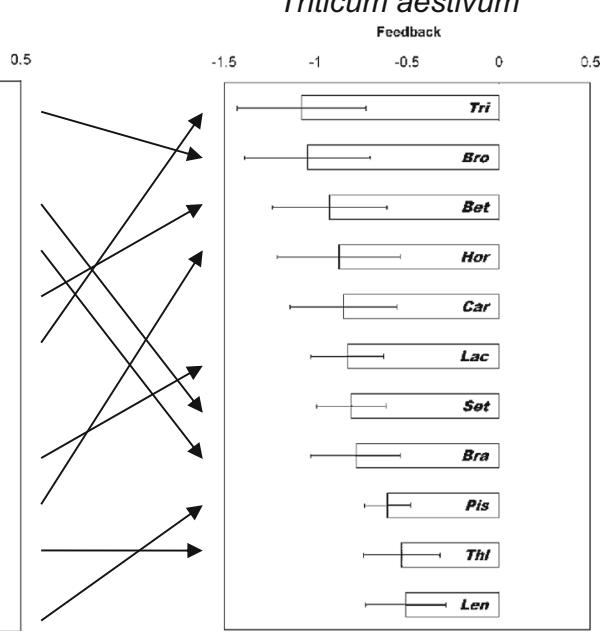

feedback values between phytometer species. Conditioning phase species are abbreviated as: Bet Beta vulgaris, Bra Brassica hirta, Bro Bromus tectorum, Car Carthamus tinctorius, Hor Hordeum vulgare, Lac Lactuca serriola, Len Lens culinaris, Pis Pisum sativum, Set Setaria viridis, Thl Thlaspi arvense, Tri Triticum 


\section{Inoculum Source}

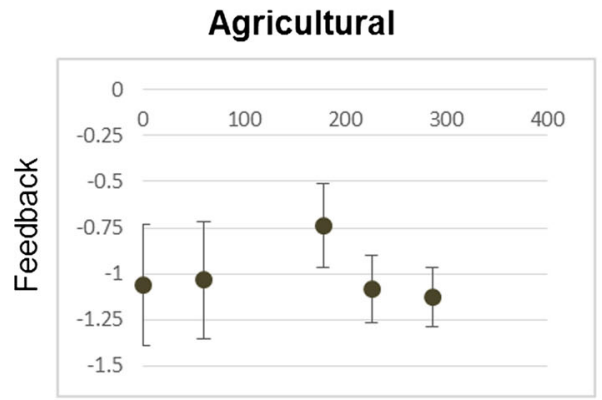

Non-cultivated pasture

Phylogenetic distance (millions of years)

Fig. 6 Relationships between phylogenetic distance, estimated in millions of years, and plant-soil feedbacks measured observed in Brassica hirta growing in pots that received either an agricultural soil inoculum (left) or a non-cultivated soil inoculum (right). Points depict the mean feedback value for a given phylogenetic

The PSFs generated by $B$. hirta on its own growth were consistently among the most growth inhibiting feedbacks measured. However, and in contrast with our last hypothesis, phylogenetic distance was not correlated with heterospecific feedbacks in soil inoculated with biota from agricultural fields but was negatively correlated with feedbacks in the non-cultivated inoculum treatment (inoculum $x$ phylogenetic distance $\mathrm{F}_{1,74}=$ 4.0, $p<0.05$ ) (Fig. 6). The increasing inhibitory effects by more distantly related species with the pasture inoculum explained $29.1 \%$ of the variation in feedbacks in this treatment. Feedbacks following $T$. arvense did not alter biomass and leguminous species generated smaller negative feedbacks than expected given their relatively close phylogenic relationship to B. hirta. Finally, conditioning by the most-distantly related species (i.e. grasses) produced some of the largest negative feedbacks (Fig. 4).

For L. culinaris, feedback values increased (i.e. were less inhibitory) with phylogenetic distance $\left(\mathrm{F}_{1,75}=24.2\right.$, $p<0.001)$ and correlation was consistent between inocula treatments $\left(\mathrm{F}_{1,75}=1.1, p>0.3\right)$ (Fig. 7). Phylogenetic distance explained $22.8 \%$ of the variation in feedback values. Conditioning by both leguminous species resulted in PSF that did not affect Lens biomass $(p>0.05$, Fig. 5). In contrast, following a grass species, the most distantly related to $L$. culinaris, PSFs increased its biomass by an average of $69 \%$ (95 C.I. 48-93\%).

In the $C$. tinctorius and $T$. aestivum response phase treatments, there were no significant correlations between feedback values in the heterospecific distance. Error bars are the $95 \%$ C.I. Significant relationships between $\ln$ (phylogenetic distance +1 ) and feedbacks in heterospecific conditioning treatments are shown in dashed lines. Feedbacks following conspecific growth (distance $=0$ ) are shown for reference but were excluded from the analysis

conditioning treatments and phylogenetic distance (LSD-Post hoc tests, $p>0.5$ ) (Fig. 7). In both cases, the lack of correlation was probably driven by speciesspecific effects that could not be explained by the phylogenetic relationships between conditioning and response phase species (Figs. 1 and 5). In C. tinctorius, while strong negative PSFs were observed when the soil was conditioned by con-specific and a closely-related species (B. vulgaris), PSFs following a con-familial weed, $L$. serriola, did not reduce its biomass. Also, PSFs in C. tinctorius following grass species varied among species The feedbacks measured in $T$. aestivum were also not explained by evolutionary relationships (Fig. 7). Pooling within families, PSFs in T. aestivum following species in Fabacaeae and Brassicaceae were less inhibitory than Poaceae $(p<0.05)$, and feedbacks following Amarathaceae and Asteraceae were similar to Poaceae.

\section{Discussion}

While significant progress has been made on assessing the importance of biologically-mediated PSFs in determining primary and secondary succession, biological invasions, and ecosystem diversity in natural settings; their ecological importance in agroecosystems is poorly understood (van der Putten et al. 2013). With increased awareness of the ecological and economic impacts of conventional agriculture, there is a growing interest in 

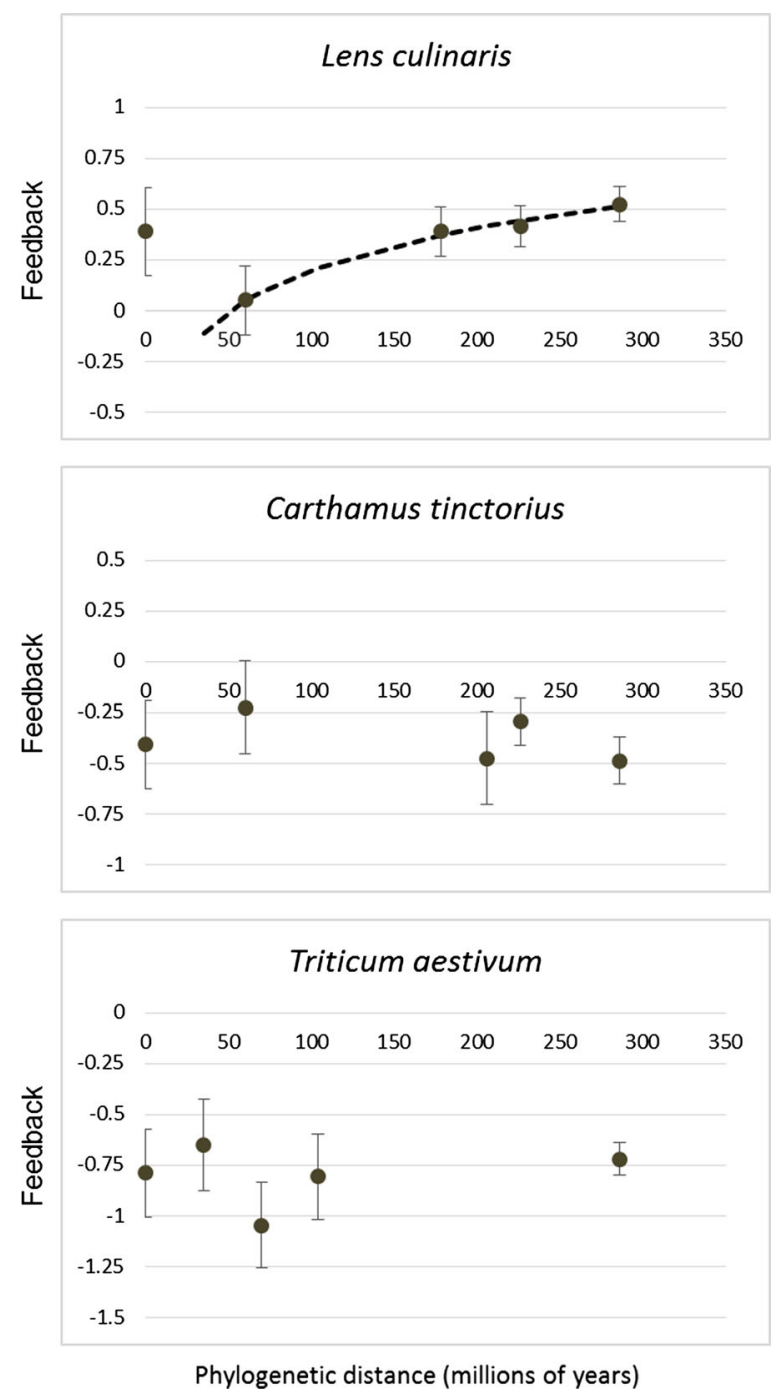

Fig. 7 Relationships between phylogenetic distance, estimated in millions of years, and plant-soil feedbacks measured observed in Lens culinaris (top), Carthamus tinctorius (center), and Triticum aestivum (bottom). Points depict the mean feedback value for a given phylogenetic distance. Error bars are the $95 \%$ C.I. Significant relationships between $\ln$ (phylogenetic distance +1 ) and feedbacks in hetero-specific conditioning treatments are shown in dashed lines. Feedbacks following conspecific growth (distance $=0$ ) are shown for reference but were excluded from the analysis

identifying alternative cropping systems that lessen the need for intensive practices while maintaining or enhancing the sustainability of the farming enterprise (Robertson and Swinton 2005). In this context, understanding the ecological role of PSFs is a key component in the development of agricultural management practices that increase soil health, reduce the impact of soilborne diseases on crops, and regulate the abundance and impact of weeds. In agroecosystems, changes in plant growth play a significant role in determining ecosystem services such as crop yield (Furhrer et al. 1992) and tolerance to intra- and inter-specific competition (Pagano et al. 2007; Vitta and Satorre 1999). While Hol et al. (2013) determined that biologically-mediated PSF can modify crop-weed competitive interactions, the extent to which species identity and phylogenetic relationships affect crops and how these PSFs vary with changes in management practices are largely unknown.

We based our first hypothesis that biologically mediated PSFs reduce annual crop growth on theoretical and empirical evidence indicating that microbially mediated PSFs vary along ecological gradients, with negative feedbacks occurring primarily in early-successional systems (Kardol et al. 2006; Klironomos 2002). Indeed, negative feedback through pathogen accumulation has long been appreciated in agriculture and is a primary rationale for crop rotation (Hwang et al. 2009). In partial agreement with our first hypothesis, with the exception of L. culinaris, most PSFs reduced plant growth. The specific behavior observed in L. culinaris could be a consequence that as a leguminous species, $L$. culinaris benefits from symbiotic associations with nitrogenfixing bacteria. Also, it could result from its symbiotic associations with arbuscular mycorrhizal fungi (Xavier and Germida 2002), with root colonization rates reaching up to $80 \%$ (Baird et al. 2010). In accordance, previous studies determined that while Glycine max (soybean), another leguminous species, showed no responses to soil microbial communities; $H$. vulgare and Brassica napus (canola) exhibit negative responses (Bainard et al. 2013).

In our study, the inhibitory effect of PSFs on the growth of T. aestivum, C. tinctorius, and B. hirta suggests that soil pathogenic organisms had a stronger effect than mutualistic ones. While this study does not allow us to provide a mechanistic explanation for the observed results, inhibitory feedbacks for these three species are consistent with previous work on their associations with soil microbes. For example, Ryan and Graham (2002) reported that arbuscular mycorrhizal fungi colonization in T. aestivum had no clear or even negative relationship with crop yield. Similarly, arbuscular mycorrhizal fungi inoculations had no or negative impacts on T. aestivum and $C$. tinctorius shoot dry mass and root length (Bryla and Duniway 1997). Finally, Glenn et al. (1985) observed that Brassica spp. roots do not form functional mycorrhizas. 
Industrialized monocultures greatly depend on managing soils with fossil-fuel based inputs of fertilizers, herbicides, and frequent mechanical disturbances. These practices, in turn, greatly impact soil biotic community and structure (reviewed by Ehrmann and Ritz 2014). Accordingly, our second hypothesis stated that biologically mediated feedbacks that develop in the cultivated agricultural field more strongly reduce plant growth than those from a less disturbed site. This was confirmed for three (L. culinaris, T. aestivum, and C. tinctorius) of the four phytometer species. When $B$. hirta was used as phytometer, the effects of inoculum source on PSFs varied across conditioning phase species treatments. Our experiment does not allow us to explain the mechanisms responsible for results observed in B. hirta and future studies could address this issue and the extent to which this result is a commonality of the Brassicaceae family.

Darwin's naturalization hypothesis that invaders closely related to residents are likely to sustain negative interactions in the introduced range (Daehler 2001) has been used to explain why phylogenetic relatedness is a critical factor determining PSFs in invaded grasslands (Brandt et al. 2009). In partial accordance with our third hypothesis, phylogenetic relatedness between conditioning and response species partially explained PSFs. While multi-cropping systems and diversified crop rotations are, in part, designed to mitigate the effects of microbial legacies on subsequent crops (Trenbath 1993; Hwang et al. 2009), the importance of the specificity in PSF among crops in rotation and among weeds and crops is seldom taken into account beyond the simple dichotomous division of grasses and dicot crops. Our results indicated that the effects of phylogenetic distance were largely driven by the strongest inhibitory PSFs occurring when the phytometer species grew in soil conditioned by the same species, supporting empirical evidences observed in crop rotation studies (Tanaka et al. 2005). However, in more distantly-related species, phylogenetic distance did not consistently predict the feedbacks across phytometer species. Future research should address the relative importance of phylogenetic relationships in determining the specificity of PSF. Such work would provide insight into the role of PSFs in determining the success of diversified crop rotations. Future studies should also explore the generality of the impacts of management systems on PSFs by replicating observations such as ours along gradients of agricultural disturbances. These future studies could also evaluate the extent to which shifts in weed communities associated with different cropping systems (Menalled et al. 2001) could impact legacies in the soil biota and alter crop growth.

A long-standing goal in sustainable agriculture is the ability to manage communities of soil biota in ways that promote plant health and productivity. In this context, soil biota could play a key role through the enhancement of positive PSFs (Bakker et al. 2013). While this study was not designed to assess the biotic shifts underlying the observed feedbacks and the lack of system replication limits the inference space of our observations, it corroborated previous observations obtained in noncropping systems on the magnitude and potential impacts of biologically mediated PSFs on plant growth. Effects observed in greenhouse conditions can be used to infer patterns that could develop in natural communities (Mokany and Ash 2008). The challenge is now to assess the extent to which our results hold in field conditions. Ultimately, an increased understanding of the impact of agricultural intensification in PSFs may provide opportunities to develop sustainable management systems.

Acknowledgments We thank Richard Smith and two anonymous reviewers for an insightful review of our work.

\section{References}

Bainard LD, Koch AM, Gordon AM, Klironomos JN (2013) Growth response of crops to soil microbial communities from conventional monocropping and tree-based intercropping systems. Plant Soil 363:345-356. doi:10.1007/s11104-0121321-5

Baird J, Walley F, Shirtliffe S (2010) Arbuscular mycorrhizal fungi colonization and phosphorus nutrition in organic field pea and lentil. Mycorrhiza 20:541-549. doi:10.1007/s00572010-0305-7

Bakker MG, Otto-Hanson L, Lange AJ, Bradeen JM, Kinkel LL (2013) Plant monocultures produce more antagonistic soil Streptomyces communities than high-diversity plant communities. Soil Biol Biochem 65:304-312. doi:10.1016/j.soilbio. 2013.06.007

Bever J (2003) Soil community feedback and the coexistence of competitors: conceptual frameworks and empirical tests. New Phytol 157:465-473. doi:10.1046/j.1469-8137.2003. 00714.x

Brandt A, Seabloom E, Hosseini P (2009) Phylogeny and provenance affect plant-soil feedbacks in invaded California grasslands. Ecology 90:1063-1072. doi:10.1890/08-0054.1

Brinkman E, Van der Putten W, Bakker E, Verhoeven K (2010) Plant-soil feedback: experimental approaches, statistical 
analyses and ecological interpretations. J Ecol 98:10631073. doi:10.1111/j.1365-2745.2010.01695.x

Bryla D, Duniway J (1997) Growth, phosphorus uptake, and water relations of safflower and wheat infected with an arbuscular mycorrhizal fungus. New Phytol 136:581-590. doi:10.1046/ j.1469-8137.1997.00780.x

Callaway R, Thelen G, Rodriguez A, Holben W (2004) Soil biota and exotic plant invasion. Nature 427:731-733. doi:10.1038/ nature 02322

Clark R, Baligar V, Zobel R (2005) Response of mycorrhizal switchgrass to phosphorus fractions in acidic soil. Commun Soil Sci Plant Anal 36:1337-1359. doi:10.1081/CSS-200056950

Curl EA (1963) Control of plant diseases by crop rotation. Bot Rev 29:413-479. doi:10.1007/bf02860813

Daehler C (2001) Darwin's naturalization hypothesis revisited. Am Nat 158:324-330. doi:10.1086/321316

Development Core Team R (2008) R: a language and environment for statistical computing. R Foundation for Statistical Computing, Vienna

de Vries F, Thebault E, Liiri M, Birkhofer K, Tsiafouli M, Bjornlund L, Jorgensen H, Brady M, Christensen S, de Ruiter P, d'Hertefeldt T, Frouz J, Hedlund K, Hemerik L, Hol W, Hotes S, Mortimer S, Setala H, Sgardelis S, Uteseny K, van der Putten W, Wolters V, Bardgett R (2013) Soil food web properties explain ecosystem services across European land use systems. Proc Natl Acad Sci U S A 110: 14296-14301. doi:10.1073/pnas.1305198110

Diez JM, Dickie I, Edwards G, Hulme PE, Sullivan JJ, Duncan RP (2010) Negative soil feedbacks accumulate over time for non-native plant species. Ecol Lett 13:803-809. doi:10. 1111/j.1461-0248.2010.01474.x

Drijber RA, Doran JW, Parkhurst AM, Lyon DJ (2000) Changes in soil microbial community structure with tillage under longterm wheat-fallow management. Soil Biol Biochem 32: 1419-1430. doi:10.1016/s0038-0717(00)00060-2

Ehrenfeld JG, Ravit B, Elgersma K (2005) Feedback in the plantsoil system. Annual Review of Environment and Resources. Annual Reviews, Palo Alto.

Ehrmann J, Ritz K (2014) Plant: soil interactions in temperate multi-cropping production systems. Plant Soil 376:1-29. doi: 10.1007/s11104-013-1921-8

Furhrer J, Grimm A, Tschannenn W, Shariatmadari H (1992) The response of spring wheat (Triticum aestivum L.) to ozone at higher elevations. 2. Changes in yield, yield components and grain quality in response to ozone flux. New Phytol 121:211219. doi:10.1111/j.1469-8137.1992.tb01106.x

Gilbert G, Webb C (2007) Phylogenetic signal in plant pathogenhost range. Proc Natl Acad Sci U S A 104:4979-4983. doi: 10.1073/pnas.0607968104

Glenn M, Chrew F, Williams P (1985) Hyphal penetration of Brassica (Crucifera) roots by vesicular-arbuscular micorrhizal fungus. New Phytol 99:463-472. doi:10.1111/j. 1469-8137.1985.tb03673.x

Hawkes CV, Kivlin SN, Du J, Eviner VT (2013) The temporal development and additivity of plant-soil feedback in perennial grasses. Plant Soil 369:141-150. doi:10.1007/s11104012-1557-0

Herms DA, Mattson WJ (1992) The dilemma of plants - to grow or defend. Q Rev Biol 67:283-335. doi:10.1086/417659

Hol W, de Boer W, ten Hooven F, van der Putten W (2013) Competition Increases Sensitivity of Wheat (Triticum aestivum) to Biotic Plant-Soil Feedback. Plos One 8. doi: 10.1371/journal.pone.0066085

Hwang S, Ahmed H, Goosen B, Kutcher H, Brandt S, Chang S, Turnbull G (2009) Effect of crop rotation on the soil pathogen dynamics and canola seedling establishment. Plant Pathol J 8:106-112. doi:10.3923/ppj.2009.106.112

Kardol P, Bezemer T, van der Putten W (2006) Temporal variation in plant-soil feedback controls succession. Ecol Lett 9:1080 1088. doi:10.1111/j.1461-0248.2006.00953.x

Klironomos J (2002) Feedback with soil biota contributes to plant rarity and invasiveness in communities. Nature 417:67-70. doi:10.1038/417067a

Kulmatiski A, Beard KH (2011) Long-term plant growth legacies overwhelm short-term plant growth effects on soil microbial community structure. Soil Biol Biochem 43:823-830. doi: 10.1016/j.soilbio.2010.12.018

Kulmatiski A, Beard KH, Stevens JR, Cobbold SM (2008) Plantsoil feedbacks: a meta-analytical review. Ecol Lett 11: 980-992. doi:10.1111/j.1461-0248.2008.01209.x

Menalled F, Gross K, Hammond M (2001) Weed aboveground and seedbank community responses to agricultural management systems. Ecol Appl 11:1586-1601. doi:10.2307/ 3061080

Mokany K, Ash J (2008) Are traits measured on pot grown plants representative of those in natural communities? J Veg Sci 19: 119-126. doi:10.3170/2007-8-18340

Nielsen D, Unger P, Miller P (2005) Efficient water use in dryland cropping systems in the great plains. Agron J 97:364-372

Pagano E, Cela S, Maddonni GA, Otegui ME (2007) Intraspecific competition in maize: Ear development, flowering dynamics and kernel set of early-established plant hierarchies. Field Crop Res 102:198-209. doi:10.1016/j.fcr. 2007.03.013

Postma-Blaauw M, de Goede R, Bloem J, Faber J, Brussaard L (2010) Soil biota community structure and abundance under agricultural intensification and extensification. Ecology 91: 460-473. doi:10.1890/09-0666.1

Reinhart K, Wilson G, Rinella M (2012) Predicting plant responses to mycorrhizae: integrating evolutionary history and plant traits. Ecol Lett 15:689-695. doi:10.1111/j.14610248.2012.01786.x

Reynolds H, Packer A, Bever J, Clay K (2003) Grassroots ecology: plant-microbe-soil interactions as drivers of plant community structure and dynamics. Ecology 84:2281-2291. doi: 10.1890/02-0298

Robertson G, Swinton S (2005) Reconciling agricultural productivity and environmental integrity: a grand challenge for agriculture. Front Ecol Environ 3:38-46. doi:10.1890/15409295(2005)003[0038:RAPAEI]2.0.CO;2

Ryan MH, Graham JH (2002) Is there a role for arbuscular mycorrhizal fungi in production agriculture? Plant Soil 244: 263-271. doi:10.1023/a:1020207631893

Sainju UM, Lenssen AW, Goosey HB, Snyder E, Hatfield PG (2010) Dryland soil carbon and nitrogen influenced by sheep grazing in the wheat-fallow system. Agron J 102:1553-1561. doi:10.2134/agronj2010.0216

Smith R, Ryan M, Menalled F (2011) Direct and indirect impacts of weed management practices on soil quality, chap 18. In: Hatfield J, Sauer J (eds) Soil management: building a stable base for agriculture. American Soc Agron and Soil Sci Soc of America, WI, p 275-286 
Stevens P (2014) Angiosperm Phylogeny Website. Available on line: http://www.mobot.org/MOBOT/Research/APweb/. Accessed 24 April 2014

Tanaka DL, Anderson RL, Rao SC (2005) Crop sequencing to improve use of precipitation and synergize crop growth. Agron J 97:385-390

Trenbath BR (1993) Intercropping for the management of pests and diseases. Field Crop Res 34:381-405. doi:10.1016/03784290(93)90123-5

van der Putten W, Bardgett R, Bever J, Bezemer T, Casper B, Fukami T, Kardol P, Klironomos J, Kulmatiski A, Schweitzer J, Suding K, Van de Voorde T, Wardle D (2013) Plant-soil feedbacks: the past, the present and future challenges. J Ecol 101:265-276. doi:10.1111/1365-2745. 12054

van Groenigen K, Bloem J, Bååth E, Boeckx P, Rousk J, Bode S, Forristal D, Jones M (2010) Abundance, production and stabilization of microbial biomass under conventional and reduced tillage. Soil Biol Biochem 42:48-55. doi:10.1016/j. soilbio.2009.09.023

Vicentini A, Barber JC, Aliscioni SS, Giussani LM, Kellogg EA (2008) The age of the grasses and clusters of origins of C(4) photosynthesis. Glob Chang Biol 14:2963-2977. doi:10. 1111/j.1365-2486.2008.01688.x

Vitta J, Satorre E (1999) Validation of a weed: crop competition model. Weed Res 39:259-269. doi:10.1046/j.1365-3180. 1999.00142.x

Wolfe B, Klironomos J (2005) Breaking new ground: soil communities and exotic plant invasion. Bioscience 55:477-487. doi: 10.1641/0006-3568(2005)055[0477:BNGSCA]2.0.CO;2

Xavier L, Germida J (2002) Response of lentil under controlled conditions to co-inoculation with arbuscular mycorrhizal fungi and rhizobia varying in efficacy. Soil Biol Biochem 34:181-188. doi:10.1016/S0038-0717(01)00165-1

Zimdahl RL (2004) Weed-crop competition: a review. Blackwell Pub, Professional, Ames 